\section{An 8}

Eine Zeitschrift der Gesellschaft Deutscher Chemiker

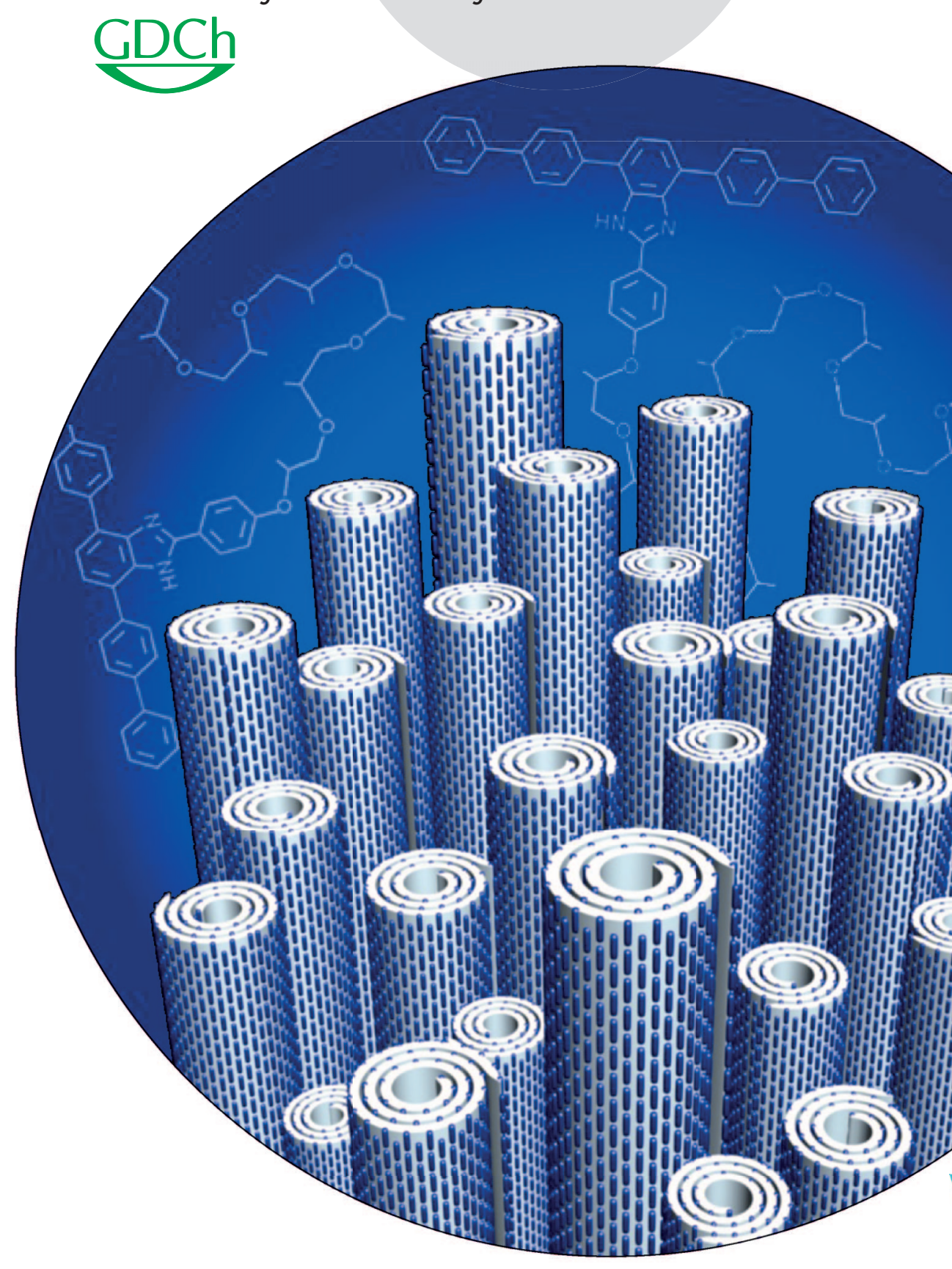

Rekonstitution von Apoenzymen

L. Fruk, C. M. Niemever et al.

Kohlenstoff-Fluor-Aktivierung

T. Braun und G. Meier

Stabile Oxoniumionen

M. M. Haley

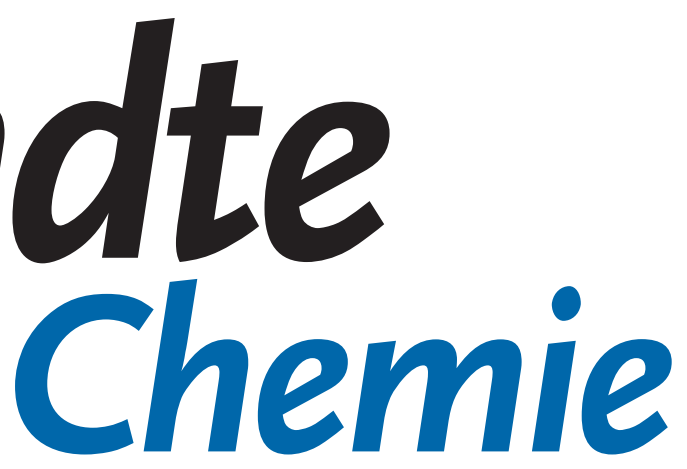

www.angewandte.de

$2009-121 / 9$ 


\section{Dong-Je Hong, Eunji Lee, Haemi Jeong, Jeong-kyu Lee, Wang- Cheol Zin, Trung Dac Nguyen, Sharon C. Glotzer und Myongsoo Lee*}

Feste Rollen bilden sich reversibel durch Selbstorganisation stabförmiger Moleküle, an die seitlich knäuelförmige Einheiten angebracht sind, im Unterschied zu Schichtstrukturen, die durch Selbstorganisation planarer Moleküle entstehen. Wie M. Lee et al. in der Zuschrift auf S. 1692 ff. schildern, lässt sich die Kernstruktur der Rollen, die entweder gefüllten Zylindern oder hohlen Röhren entsprechen, durch Variation der Länge der Knäuel-Einheit steuern. Das Titelbild zeigt ausgerichtete röhrenförmige Rollen mit wohldefinierter Ordnung der Stabsegmente innerhalb einer Ebene.

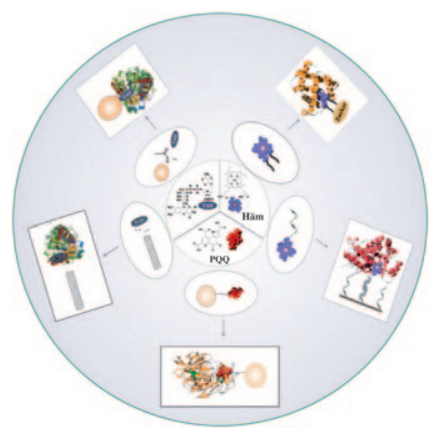

\section{Enzymrekonstitution}

L. Fruk, C. M. Niemeyer et al. berichten im Aufsatz auf S. 1578 ff., wie durch Austausch nativer gegen künstliche Cofaktoren halbsynthetische Enzyme entstehen, die bessere oder neue Aktivitäten aufweisen oder zum Studium von StrukturFunktions-Beziehungen eingesetzt werden können.

\section{Solarzellen}

In ihrer Zuschrift auf S. 1604 ff. beschreiben L. Sun, M. K. Nazeeruddin et al. eine ungewöhnlich stabile Solarzelle, die aus einem maßgeschneiderten organischen Farbstoff aufgebaut wurde.

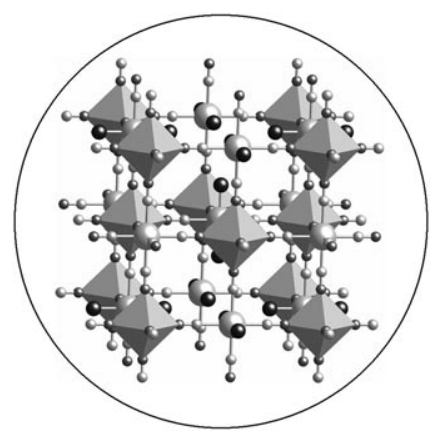

\section{Preußischblau-Analoga}

R. Lescouëzec et al. stellen in der Zuschrift auf S. 1701 ff. Festkörper- ${ }^{113}$ Cd-NMRStudien an $\left[\mathrm{Cd}_{3}\left\{\mathrm{Fe} / \mathrm{Co}(\mathrm{CN})_{6}\right\}_{2}\right] \cdot 15 \mathrm{H}_{2} \mathrm{O}$ vor. Dessen Leerstellen sind nicht zufällig verteilt, und die Spindichte am $\mathrm{Cd}^{2+}$ variiert mit der Zahl an umgebenden paramagnetischen Ionen.

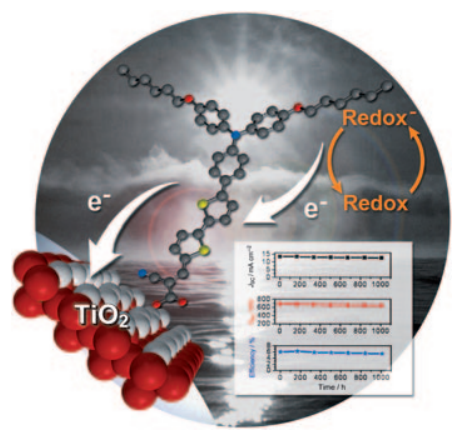

